TAO, Vol. 11, No. 4, 879-894, December 2000

\title{
Surface Erythemally-weighted UVB Flux in Taiwan
}

\author{
Chung-Ming Liu ${ }^{1, *}$
}

(Manuscript received 13 February 2000, in final form 21 August 2000)

\begin{abstract}
Based on data collected from January 1996 to May 2000, this paper outlines a general climatology of the noontime maximum ultra-violet index (UVI) in Taiwan. In summer, high UVI values of 14 15 can be observed at a $2400 \mathrm{~m}$-high mountain site and at southern and eastern coastal sites. It is noted that Taipei, a polluted city, has only a $19 \%$ chance of observing a UVI over 9 in July, while Hualien, a clean coastal city, has an $83 \%$ chance. In addition, total ozone has a minor spatial variation pattern and is not the major factor affecting the change in surface UVB flux. Flux transmissivity, which is estimated by dividing the observed UVI with a model-estimated value for a clear sky condition, has a positive correlation coefficient of 0.73 $\sim 0.84$ with the UVI, which supports the idea that clouds and local pollution strongly affect the surface UVB flux. A UVI forecast system is developed based on the findings stated above. Forecast of total ozone is simplified, while subjective and objective cloud-effect adjustment processes are emphasized. The root-mean-square difference between the forecast and observed UVI is about $1.7 \sim 2.9$, with a correlation coefficient of $0.6 \sim 0.76$ and a bias of $\mathbf{- 0 . 5 4} \sim 0.5$. The worst forecast is at Alishan, the mountain site, because the local fast-changing weather is difficult to forecast.
\end{abstract}

(Key words: Ultra-violet B flux, UV-index, Climatology, Forecast)

\section{INTRODUCTION}

After the discovery of the Antarctic ozone hole, monitoring surface UVB flux and forecasting daily noontime maximum UV index (UVI) emerged as new tasks for government agencies around the world. The World Ozone Data Center in Canada was renamed in June 1992 to become the World Ozone and Ultraviolet Radiation Data Center. In the meantime, issues such as comparing UV spectrometer and radiometer measurement data (Leszczynski et al. 1998), analyzing long-term UV trends (Kerr and McElroy 1993; Borkowski et al. 1998),

\footnotetext{
${ }^{1}$ Dept. of Atmospheric Sciences, National Taiwan University, Taipei, Taiwan, ROC

* Corresponding author address: Prof. Chung-Ming Liu, Dept. of Atmospheric Sciences, National Taiwan University, \#1, section 4, Roosevelt Road, Taipei, Taiwan, ROC

E-mail: liucm@ccms.ntu.edu.tw
} 
modeling UV radiative transfer (Koepke et al. 1998), developing UVI forecast methodology (Austin et al. 1994; Long et al. 1996; Jendritzky et al. 1997), have attracted the attention of many scientists. To standardize the UV index, the World Meteorological Organization convened a meeting of experts on UV indices in 1994 (WMO 1995). The standard for the UV index was defined by WMO as the solar noon erythemally weighted dose divided by 25 $\mathrm{mWm}^{-2}$.

In 1992, the Central Weather Bureau (CWB) set up two Brewer Spectrometers in Taiwan, at Taipei and Chengkung (see Fig. $l$ and Table 1), to monitor the column total ozone (Liu et al. 1995). The spectrometer measures spectral UVB irradiance, which can be weighted by the CIE Erythema Action Spectrum (McKinlay and Diffey 1987) and integrated to provide a reliable UVB dose rate (McElroy et al. 1994; Bais 1997). In May 1997, a UVI forecast system was put into service by the Environmental Quality Protection Foundation (a nonprofit organization) and the Global Change Research Center of National Taiwan University (Liu and Liu 1997). The Environmental Protection Adminis ation (EPA) of the Executive Yuan took

(a)

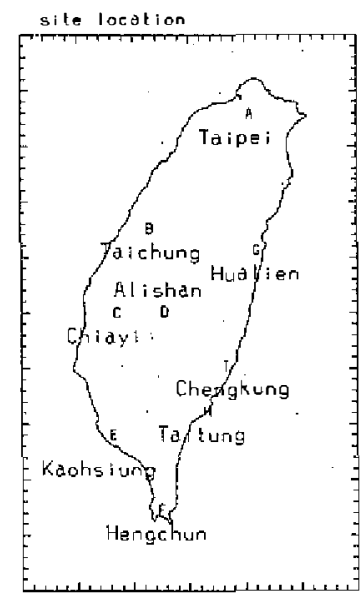

(c)

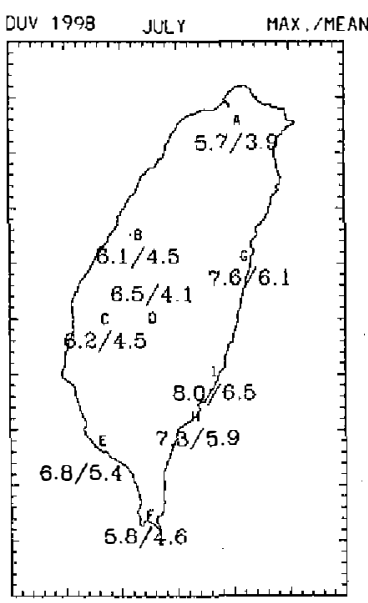

(b)

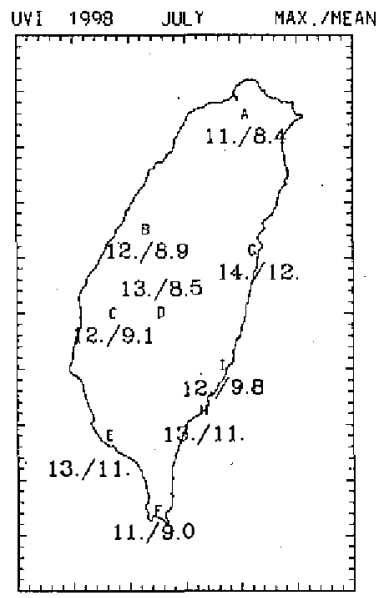

(d)

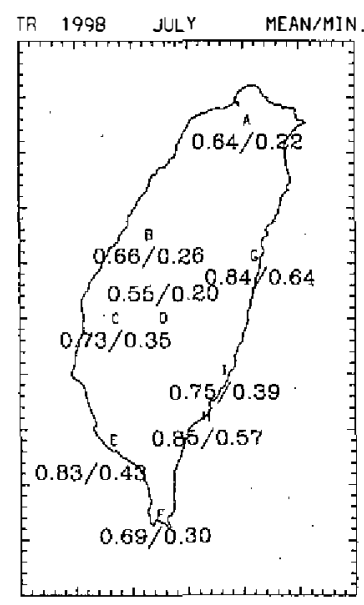

Fig. 1. (a) Site location, details are shown in Table 1; (b) the monthly-maximum and mean UV index, (c) the monthly-maximum and mean daily erythemal dose (DUV; $\mathrm{KJ} \mathrm{m}^{-2}$ ) and (d) the monthly-mean and minimum flux transimissivity (Tr) in July 1998. 
Table 1. UVI monitoring sites and basic information.

\begin{tabular}{|c|c|c|c|c|c|c|c|c|c|}
\hline & $A^{1}$ & $\mathrm{~B}^{2}$ & $\mathrm{C}^{2}$ & $D^{2}$ & $E^{2}$ & $F^{2}$ & $G^{2}$ & $\mathrm{H}^{2}$ & $\mathrm{l}^{3}$ \\
\hline & Taipei & Taichung & Chiayi & Alishan & $\overline{\text { Kaohsiung }}$ & Hengchun & Hualien & Taitung & Chengkung \\
\hline Latitude ${ }^{\circ} \mathrm{N}$ & 25.03 & 24.15 & 23.5 & 23.51 & 22.57 & 22 & 23.98 & 22.75 & 23.1 \\
\hline Longitude ${ }^{\circ} \mathbf{E}$ & 121.51 & 120.68 & 120.41 & 120.8 & 120.3 & 120.73 & 121.6 & 121.15 & 121.3 \\
\hline Altitude $\mathrm{m}$ & 6 & 84 & 27 & 2413 & 2 & 22 & 16 & 9 & 34 \\
\hline Data period & $\begin{array}{l}/ 1 / 96 \sim \\
5 / 31 / 00\end{array}$ & $\begin{array}{l}12 / 1 / 97 \sim \\
5 / 31 / 00 \\
\end{array}$ & $\begin{array}{l}4 / 1 / 98 \sim \\
5 / 31 / 00 \\
\end{array}$ & $\begin{array}{l}5 / 1 / 97 \sim \\
5 / 31 / 00 \\
\end{array}$ & $\begin{array}{l}4 / 1 / 98 \sim \\
5 / 31 / 00 \\
\end{array}$ & $\begin{array}{l}5 / 1 / 97 \sim \\
5 / 31 / 00 \\
\end{array}$ & $\begin{array}{l}4 / 1 / 98 \sim \\
5 / 31 / 00 \\
\end{array}$ & $\begin{array}{l}4 / 1 / 98 \sim \\
5 / 31 / 00 \\
\end{array}$ & $\begin{array}{l}.1 / 1 / 96 \sim \\
5 / 31 / 00 \\
\end{array}$ \\
\hline \multicolumn{10}{|c|}{ UVI } \\
\hline Maximum UV] & 11.4 & 12.5 & 12.2 & 14.4 & 14.8 & 13.1 & 14.3 & 13.4 & 13.8 \\
\hline Mean UVI & 4.6 & 5.6 & 5.8 & 6.3 & 7.5 & 7.1 & 6.6 & 7.6 & 6.8 \\
\hline$\sigma$ (s.d.) & 2.5 & 2.3 & 2.5 & 3.1 & 3.1 & 2.6 & 3.3 & 3.3 & 3.2 \\
\hline \multicolumn{10}{|c|}{ Correlation coefficient with total ozone $\left(\Omega_{\mathrm{O}_{3}}\right)$} \\
\hline UVI \& $\Omega_{\mathrm{O}_{3}}$ & 0.43 & 0.35 & 0.41 & 0.11 & 0.46 & 0.36 & 0.25 & 0.40 & 0.41 \\
\hline \multicolumn{10}{|c|}{ Correlation coefficient with total ozone $\left(\Omega_{\mathrm{O}_{3}}\right) / \cos ($ zenith angle) } \\
\hline UVI \& $\Omega \mathrm{O}_{3} / \cos \theta$ & -0.53 & -0.54 & -0.57 & -0.27 & -0.56 & -0.53 & -0.54 & -0.55 & -0.53 \\
\hline \multicolumn{10}{|c|}{ Daily erythemal dose (DUV; $\mathrm{KJ} \mathrm{m}^{-2}$ ) } \\
\hline Maximum D̈UV & 6.1 & 6.1 & 6.2 & 7.0 & 7.2 & 6.8 & 7.6 & 7.3 & 8.8 \\
\hline Mean DUV & 2.1 & 2.6 & 2.7 & 2.9 & 3.5 & 3.3 & 2.9 & 3.5 & 3.8 \\
\hline$\sigma($ s.d. $)$ & 1.3 & 1.3 & 1.3 & 1.4 & 1.7 & 1.4 & 1.7 & 1.8 & 2.2 \\
\hline \multicolumn{10}{|c|}{ Transmissivity (Tr) } \\
\hline Minimum Tr & 0.02 & 0.06 & 0.01 & 0.02 & 0.03 & 0.01 & 0.03 & 0.02 & 0.02 \\
\hline Mean $\mathbf{T r}$ & 0.47 & 0.57 & 0.68 & 0.6 & 0.72 & $\overline{0.68}$ & 0.64 & 0.72 & 0.65 \\
\hline$\sigma($ s.d. $)$ & 0.21 & 0.18 & 0.19 & 0.27 & 0.21 & 0.19 & $0 . \overline{26}$ & $0 . \overline{24}$ & $0 . \overline{24}$ \\
\hline \multicolumn{10}{|c|}{ Correlation coefficient of $\mathrm{Tr}$ with some parameters } \\
\hline Tr \& UVI & 0.84 & 0.73 & 0.73 & 0.79 & 0.81 & 0.73 & 0.83 & 0.81 & 0.83 \\
\hline Tr \& visibility & 0.52 & 0.32 & 0.54 & 0.69 & 0.54 & 0.54 & 0.61 & 0.68 & 0.53 \\
\hline $\begin{array}{r}\text { Tr \& cloud } \\
\text { amount }\end{array}$ & -0.66 & $-0.6 \mathrm{l}$ & -0.70 & -0.75 & -0.50 & -0.70 & -0.61 & -0.73 & -0.72 \\
\hline Tr \& RH & -0.61 & -0.58 & -0.64 & -0.75 & -0.45 & -0.64 & -0.42 & -0.42 & -0.35 \\
\hline $\begin{array}{r}\text { Tr \& Sunshine } \\
\text { duration hour }\end{array}$ & 0.75 & 0.70 & 0.79 & 0.83 & 0.71 & 0.79 & 0.77 & 0.83 & 0.79 \\
\hline \multicolumn{10}{|c|}{ Noontime Cloud amount (Cld) } \\
\hline Mean Cld & 0.81 & 0.62 & 0.61 & 0.76 & 0.51 & 0.61 & 0.68 & 0.66 & 0.70 \\
\hline$\sigma$ (s.d.) & 0.25 & 0.34 & 0.29 & 0.26 & 0.33 & 0.29 & 0.32 & 0.31 & 0.28 \\
\hline
\end{tabular}

Spectrometer data during Jan. $1996 \sim$ April 1997 ; Radiometer data after May 1997.

${ }^{2}$ Radiometer data. $\quad{ }^{3}$ Spectrometer data.

over daily operation of UVI forecasting in July 1998. Many new UVB monitoring sites have been set up to assist in the improvement of the UVI forecast system (Liu et al. 1998). Each station uses a Solar Light Co. Model 501 Biometer to provide directly an erythemally-weighted UVB dose rate. By May 31, 2000, at least 25 months data had been archived at nine CWB stations (Table 1). It is worth noting that the Brewer Spectrometer is operated manually under conditions of no-rain and gives an instant output, while the Solar Biometer provides the hourly- 
mean value continuously. Hence, the former tends to give a slightly higher value. At Taipei, output from two different monitoring systems has been available since May 1997. From May 1997 through May 2000, the root mean square of the difference between UVI measured by the Solar instrument and that by the Brewer is 0.86 , which is about $16 \%$ of the Brewer mean value of 5.21, while the correlation coefficient between these two datasets is 0.98 . UVI from the Brewer is about 0.6 higher than the Solar value. This analysis agrees with the conclusion reached by Leszczynski et al. (1998) that, with strict quality assurance/quality control procedures, the accuracy of the temperature-controlled erythemally weighted radiometers is not significantly worse than that of spectroradiometers.

In this paper, noontime maximum UVI data collected at nine different stations are analyzed. Meanwhile, to study the attenuation effect of cloud and air pollutants, a flux transmissivity is retrieved by dividing the observed UVI with a model-estimated value for a clear-sky condition. In addition, the UVI forecast system is elaborated on in detail.

\section{DATA ANALYSIS}

UVI at nine stations have a range between $4.6 \pm 2.6$ and $7.6 \pm 3.3$ (Table 1, Fig. 1a). High indices appear at Taitung and Hualien, both located on the clean eastern coast, while at Taipei, a polluted city in northern Taiwan, the values are low. UVI larger than 9 occur at all stations, mainly during February October (Fig. 2a). Among these stations, maximum UVI of larger than 14 have been observed at Kaohsiung, Alishan and Hualien. Alishan is a mountain site at $2400 \mathrm{~m}$ altitude, while Kaohsiung is on the southwest coast. As expected, summer has the highest monthly-mean UVI and the winter months record low indexes. Fig. 1a illustrates the spatial distribution of maximum and mean UVI in July 1998. Differences in local pollution and weather conditions are crucial in determining the spatial variation in UVI.

The frequency of UVI of between 10 and 15 (Fig. 2a) peaks in July and August. Hualien has the highest frequency with $83 \%$ in August, while in the same month Taipei has none. As to the occurrence of UVI less than 2, Taipei has the highest chance of nearly $95 \%$ in December and January, while in the same period Hualien has only $60 \%$. In all, Taipei has the highest chance (47\%) of observing UVI less than 5, while Taitung and Kaohsiung have the highest chance (30 35\%) of observations over 9 . Both spatial and temporal variations of UVI in Taiwan are quite significant.

Calculation of the cross-correlation coefficient of UVI between different stations shows a high correlation among stations other than Taipei and Alishan, suggesting that factors causing the variation of UVI at most stations are very similar, e.g., the synoptic weather system. At Taipei and Alishan, on the other hand, local pollution or terrain-forced circulation plays an important role in affecting the surface UVB flux. Interestingly, the correlation coefficient between surface UVI and total ozone is only about $0.25 \sim 0.46$ (excluding Alishan), but it becomes $-0.53 \sim-0.57$ when UVI is correlated to the total ozone value divided by the cosine of zenith angle $(\cos \theta)$ (Borkowski 2000). The weak positive correlation between UVI and total ozone seems to suggest a weak correlation between these two values, but by dividing total ozone by $\cos \theta$, we have a value be embedded with the same solar seasonal cycle as UVI and 
(a)

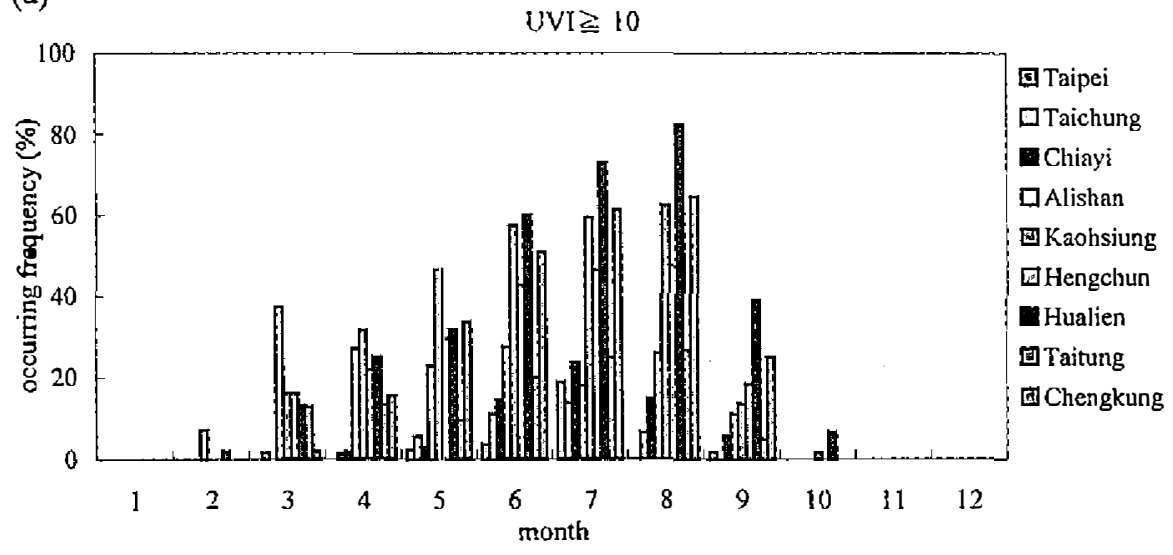

(b)

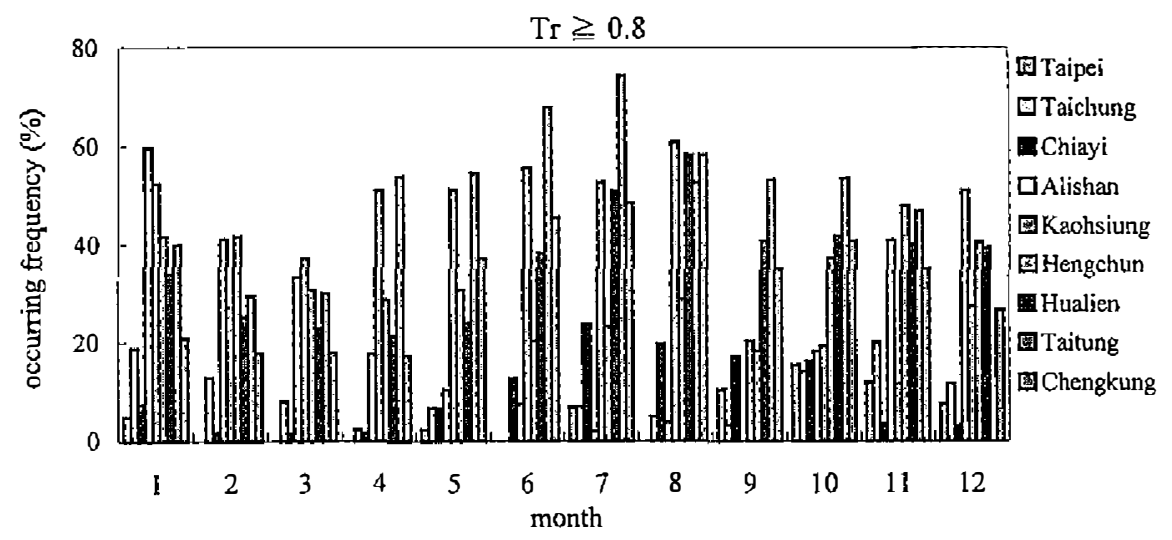

Fig. 2. Monthly variation of the occurring frequency of (a) UVI $\geq 10$ and (b) flux transmissivity $(\mathrm{Tr}) \geq 0.8$.

hence a clarified negative correlation, which implies that the decrease of column ozone amount does enhance the surface UVB flux. Still, the correlation coefficient is not large enough to suggest that the variation of total ozone is the only factor affecting the change in UVI.

The total ozone data (not shown here) are monitored daily by Brewer spectrometers at Taipei and Chengkung. From 1992 through 1999, total ozone ranged between 200 330 D.U. with peak levels in April May and minima in November January. The root mean square difference between these two stations' data is 12 D.U., which is about $4.5 \%$ of the long-term mean of 266 D.U. On average, the column ozone over Taipei is about 6 D.U. higher than that over Chengkung, while the correlation coefficient between these two data sets is 0.86 . Since Taipei and Chengkung are essentially along the same meridional line but $200 \mathrm{~km}$ apart in latitude, this suggests that column ozone plays a less important role than other factors, such as clouds, on the spatial variation of UVI over Taiwan. 
Seckmeyer et al. (1995) compared the daily integrals of erythemal flues (DUV, $\mathrm{kJ} \mathrm{m}^{-2}$ ) at 12 stations worldwide and noted that geographic differences were much larger than the measurement uncertainties. This study shows that DUV is a useful parameter for comparing the surface UVB flux reached at different locations on the globe. In Taiwan, mean DUV range between $2.1 \pm 1.3 \sim 3.5 \pm 1.8$ with maxima of between $6.1 \sim 8.8 \mathrm{~kJ} \mathrm{~m}^{-2}$ (Table 1). July-maximum DUV of $7.3 \sim 7.6 \mathrm{~kJ} \mathrm{~m}^{-2}$ at Hualien and Taitung are higher than those observed at San Diego $\left(32.5^{\circ} \mathrm{N}\right)$ in July and close to that recorded at Darwin $\left(12.5^{\circ} \mathrm{S}\right)$ in November. The highest July-mean DUV of $6.1 \mathrm{~kJ} \mathrm{~m}^{-2}$ is at Hualien, which is higher than the July-mean at San Diego and the November-mean at Darwin. The data for San Diego and Darwin are available in Seckmeyer et al. (1995). The lowest July-maximum DUV of $5.7 \mathrm{~kJ} \mathrm{~m}^{-2}$ is at Taipei, with a July-mean DUV of $3.9 \mathrm{~kJ} \mathrm{~m}^{-2}$ which is close to that measured at Melbourne $\left(37.8^{\circ} \mathrm{S}\right)$ during winter. It is noted that the latitudinal difference between Taipei and Taitung is about $2.28^{\circ}$, but the equivalent latitudinal difference between the surface UVB flux received at theses two stations is about $25.3^{\circ}$. Clearly, the spatial variation of UVB flux in Taiwan is quite significant. This is further illustrated in Fig. 1b which shows the monthly-maximum and mean DUV in July 1998.

As expected the noontime flux contributes the major portion of the daily integral of erythemal flux. Analyses show that the noontime (10am - 2pm) integral of erythemal flux contributes about $50 \sim 75 \%$ of the daily integral, with a lower percentage in summer and a higher one in winter and spring.

\section{FLUX TRANSMISSIVITY}

In this section, a reduction factor for erythemally-weighted UVB flux is calculated and named as the flux transmissivity (Tr) of UVB flux passing through clouds and air pollutants ( $\mathrm{SO}_{2}$ and aerosol). A radiative transfer model UVSPEC is used to calculate the surface UVB spectral irradiance at each wavelength between $290 \mathrm{~nm}$ and $400 \mathrm{~nm}$ for clear-sky noontime conditions. These spectral irradiances are then weighted by the CIE action spectrum (McKinley and Diffey 1987) and are integrated to generate an erythemal irradiance $\left(\mathrm{mW} \mathrm{m}^{-2}\right)$ or dose rate, which is then divided by 25 to give a UV index (WMO 1995). The UVSPEC package developed by Kylling et al. (1995) comprises three different radiative transfer solvers (Kylling 1995). The general-purpose discrete ordinate algorithm, DISORT, is selected for our radiative transfer calculation (Liu et al. 1998). The model intercomparison study done by Koepke et al. (1998) indicates that results of this model's calculation are not significantly different from those obtained by other multiple-scattering spectral models. Since the development of the radiative transfer model has been quite successful and can provide accurate calculations, the major source of inaccuracy should be from the input data. These include column ozone amount, ozone profile, aerosol optical depth, single scattering albedo and ground albedo (Weihs and Webb 1997a,b; Schwander et al. 1997). In the calculation, daily spatial-mean total ozone and the long-term monthly-mean ozone profiles measured by Vaisala ozone sonde at Taipei (Liu et al. 1995) are used. The ozone profile is adjusted with respect to the daily total ozone amount. Meanwhile, the ground albedo is set at 0.02 for vegetation conditions, as suggested by Feister 
and Grewe (1997), and the background clean environment with visibility of $95 \mathrm{~km}$ is applied. Table 1 shows that $\operatorname{Tr}$ values are between $0.47 \pm 0.21$ and $0.72 \pm 0.24$. The lowest value is about $0.01 \sim 0.09$. As expected, Taipei has the lowest transmissivity, with a $72 \%$ chance of occurring in the $0.3 \sim 0.8$ range, whereas Taitung has the highest transmissivity with a $51 \%$ chance of being over 0.8 . The contrast is quite significant. Clearly, a positive correlation exists between $\mathrm{Tr}$ and UVI. Table 1 shows that the correlation coefficient is about $0.73 \sim 0.84$. In comparison with the low correlation of -0.55 between UVI and the total ozone divided by cos $\theta$, the importance of local meteorological conditions on attenuating the UVB flux is clearly evident (Liu et al. 1998). Meanwhile, Fig. 2 shows that UVIs over 9 occur mainly between May and August, while Tr values over 0.8 appear in all months and are generally more frequent between May and August. For instance, Taitung's highest occurring frequency of $74 \%$ is in July, Kaohsiung's at $61 \%$ and Hualien's at $58 \%$ are in August. Still, Alishan has its highest chance of $60 \%$ in January, Hengchun in November (47\%), Taipei in October (16\%).

Further analysis of the variation of $\operatorname{Tr}$ with surface meteorological parameters shows that $\operatorname{Tr}$ varies positively with visibility and sunshine duration hours, but negatively with cloud amount and relative humidity (Table 1). This result indicates the importance of weather variation to the change in Tr. Among all surface meteorological parameters, noontime cloud amount appears to be the dominant factor affecting surface UVB flux. Table 1 shows that Taipei and Alishan have the highest mean cloud amount of $0.76 \sim 0.81$ with the highest chance $(>69 \%)$ of observing cloud amount over 0.8 and the lowest chance $(\leq 8 \%)$ of observing cloud amount less than 0.2 . Whereas high UVI stations along east and south coasts have a much lower chance of observing high cloud amount but higher chance of observing low cloud amount. Among these high UVI stations, Kaohsiung, the second most populated city in Taiwan, has a mean noontime cloud amount of 0.51 and a $34 \%$ chance of observing cloud amount less than 0.3 . Hence, even though Kaohsiung is also a polluted city, mean $\operatorname{Tr}$ at Kaohsiung is much larger than that at Taipei.

\section{UVI FORECAST SYSTEM}

The UVI forecast system in Taiwan has been in operation since May 1997. AT first, it forecast next-day noontime maximum UVI at 16 locations. After May 1998, the system was modified to forecast UVI at 200 grids for the Intemet release of an islandwide UVI plot (Fig. 3 ) and the public announcement of UVI at 49 selected locations. The system which is summarized in Fig. 4, consists of four major processes: data input, calculation of next-day clear-sky noontime maximum UVI, objective and subjective cloud-effect adjus ment, and output of forecast results.

The task of next-day total ozone forecast is quite simple. We first get today's spatial-mean total ozone, i.e., the averaged Taipei and Chengkung total ozone. Then the ratio between today's value and the long-term mean is used to forecast the next day's total ozone by multiplying the ratio with the next day's long-term mean. To check the error caused by using the daily spatialmean total ozone, the clear-sky noontime UVI at Taipei during the period 1996 through 1997 has been calculated for three different conditions, i.e., using the observed total ozone, the 


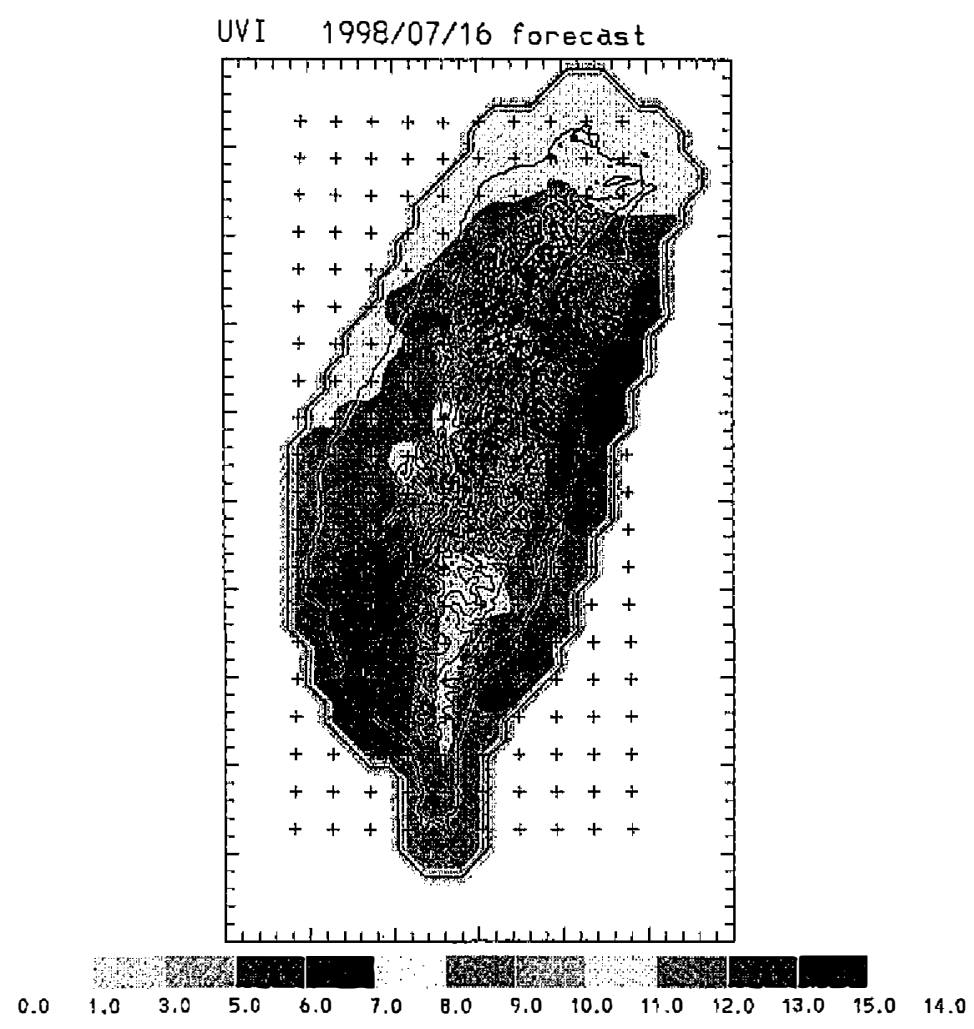

Fig. 3. UVI at 200 grids, each marked by a cross, are forecast daily to generate a contour plot over Taiwan. The dimensions of each grid are $22 \mathrm{~km}$ by $20 \mathrm{~km}$.

spatial-mean total ozone, and the spatial-mean total ozone estimated by the method described above. As shown in Table 2, the latter two outputs differ slightly from the former one by a root mean square (rms) difference of 0.32 and 0.47 , and a bias of 0.25 and 0.42 , respectively. Furthermore, if we separate the whole two years' data into four different seasons, it appears that the differences are higher in summer and lower in winter. By comparing the rms difference with the mean UVI, the ratio is only about $5 \%$. Thus, even if the daily total ozone level can be forecast very accurately, the estimated clear-sky noontime maximum UVI will improve only slightly. Such minor improvement is less important than the errors embedded in the daily total ozone forecast and the cloud effect on attenuating the UV flux. In future, a total ozone forecast system will be developed, as done by Long et al. (1996), Kerr et al. (1997), among others, as a lower priority project.

To estimate the next-day cloud attenuating effect on UVI, an empirical equation was developed to objectively adjust the cloud-effect, i.e.,

$$
u_{i+1}^{f}=u_{i+1}^{c}-a_{0}-a_{1} \Delta u_{i}-a_{2} P_{i+1}-a_{3} T_{i+1}^{\max }-a_{4} \Delta T_{i+1},
$$

where $i+1$ stands for next day; $i$ stands for today; $\mathbf{u}_{i+1}^{\mathrm{f}}$ is the next-day UVI forecast value; $\mathrm{u}^{\mathrm{c}}{ }_{\mathrm{i}+1}$ is the next-day calculated clear-sky maximum UVI; $\Delta$ ui is the deviation of today's calculated 


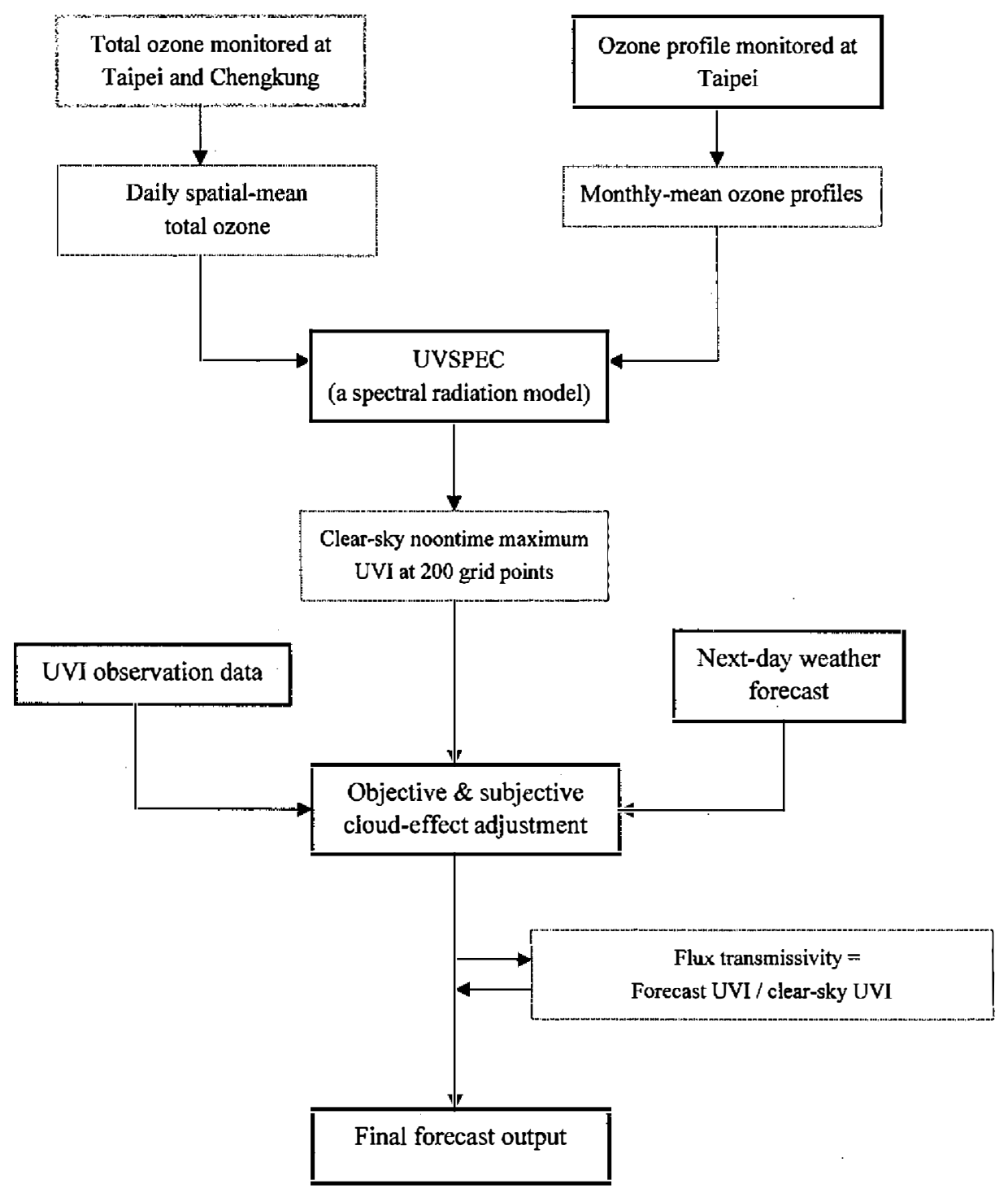

Fig. 4. A structure diagram of the Taiwan UVI forecast system.

clear-sky noon-time maximum UVI from the observed maximum UVI; $P_{i+1}$ is the next-day forecast precipitation probability; $T^{\max }{ }_{i+1}$ is the next-day forecast maximum temperature; $\Delta T_{i+1}$ is the next-day forecast temperature range between the maximum and the minimum temperature. The coefficients $a_{0} \sim a_{4}$ can be updated every six months. At most of the UVI observation sites, Eq. (1) maintains a correlation coefficient of over 0.7 . In this regard, we note that the next-day maximum temperature, minimum temperature, precipitation probability and weather pattern over thirteen inland areas and three major outlying island regions are forecast daily by the Central Weather Bureau. However, there is no quantitative forecasting information about cloud 
Table 2. The calculated clear-sky noontime UVIs at Taipei during 1996-1997 for three different conditions: (1) the daily observed total ozone at the same location, (2) the spatial-mean total ozone, and (3) the spatial-mean total ozone estimated by the method outlined in the pape. The bias and root-mean-square error of (2) and (3) from (1) are estimated and listed.

\begin{tabular}{|c|c|c|c|c|c|c|c|c|c|c|c|c|c|c|c|}
\hline & \multicolumn{3}{|c|}{ Winter } & \multicolumn{3}{|c|}{ Spring } & \multicolumn{3}{|c|}{ Surnmer } & \multicolumn{3}{|c|}{ Autumn } & \multicolumn{3}{|c|}{$1996 \sim 1997$} \\
\hline & $\begin{array}{c}\text { Mean } \\
\text { UVI }\end{array}$ & bias & rms & $\begin{array}{c}\text { Mean } \\
\text { UVI }\end{array}$ & bias & rms & $\begin{array}{l}\text { Mean } \\
\text { UVI }\end{array}$ & bias & mis & $\begin{array}{l}\text { Mean } \\
\text { UVI }\end{array}$ & bias & rms & $\begin{array}{l}\text { Mean } \\
\text { UVI }\end{array}$ & bias & $\mathrm{rms}$ \\
\hline (i) & 7.2 &. & . & 8.4 & . & - & 12.3 & - & - & 12.4 & - & - & 10.3 & - & . \\
\hline (2) & 7.2 & 0.18 & 0.23 & 8.4 & 0.14 & 0.20 & 12.6 & 0.24 & 0.31 & 12.8 & 0.19 & 0.44 & 10.3 & 0.25 & 0.32 \\
\hline (3) & 7.2 & 0.30 & 0.32 & 8.5 & 0.38 & 0.46 & 12.6 & 0.46 & 0.51 & 12.8 & 0.49 & 0.54 & 10.3 & 0.42 & 0.47 \\
\hline
\end{tabular}

amount and cloud type, which are extremely important for improving the forecast.

Two factors are important to implement Eq. (1). These are UVI observation and weather forecasts at each forecast point. Unfortunately, there are only a limited number of UVI observation sites, while weather forecasts are not for a specific point but a general area. For these reasons, it was decided to adjust the UVI forecast for local effect, first at existing observation sites, and then interpolate or extrapolate flux transmissivity, $\operatorname{Tr}$, to other forecast points. Here, $\operatorname{Tr}$ is defined as the ratio of $u_{i+1}^{f}$ to $u_{i+1}^{c}$. Clearly, the quality of UVI forecasts will improve with the increase in the number of UVI observation sites in the future. Between May 1997 and April 1998, the first-generation forecast system used only four UVI observation sites. Only Taipei and Chengkung have enough historical UVI data to generate $\mathrm{a}_{\mathrm{o}} \sim \mathrm{a}_{4}$ coefficients. During that period, 16 forecast points were selected. The coefficients used at the other 14 sites were determined subjectively based on the coefficients at Taipei and Chengkung. After April 1998, the number of monitoring sites increased to 9 and by the mid-1999, the total was over 25 . The $a_{0} \sim a_{4}$ coefficients at each site can now be determined based on each site's own observations.

From May through August 1997, i.e., the first four months of UVI forecasts, the disadvantage of the objective adjustment scheme was noticed. Often, a fairly reasonable prediction is obtained when the synoptic weather conditions vary moderately. However, some unexpected weather conditions, such as a fast moving cold front, can easily make the observed UVI stray considerably from the forecast level. To enhance forecast reliability, an experienced meteorologist was invited to subjectively modify the forecast UVI after the objective adjustment is applied. This turned out to be a valuable way of cutting down the incidence of incorrect forecast during extreme weather change, and of improving considerably the forecasts at mountain sites. For example, from August 28, 1997 to April 26, 1998, the rims difference between the forecast and observed UVI at four observation sites, with and without applying the subjective adjustment approach are compared. These four sites are at Taipei, Chengkung, Alishan and Hengchun. The rms in the former case is 1.78, 1.95, 2.88 and 1.96, respectively, while it is $2.09,1.85,3.27$, and 2.50, respectively, for the latter one. Except at Chengkung, lowering of the rms difference after applying the subjective adjustment is obvious. This is particularly important at Alishan, the mountain site, where the rms value is down from 3.27 to 
2.88. Since the weather forecast information over the mountain region is unreliable; the improvement at Alishan is most valuable. The slight increase of rms difference at Chengkung is not statistically significant.

Comparison of the forecast UVI with observed in five different ranges at the four sites are shown in Table 3. If the forecast UVI does not match closely with the observed value, we hope they match in a close range. Table 3a suggests that without applying the subjective adjustment, the range match is good for the moderate and high range and worse in the low range. The

Table 3. Net number of forecast UVI at Taipei, Chengkung, Alishan, Hengchung and Taichung, compared with those observed in five different ranges. during May 1997 April 1998, (a) without and (b) with applying the subjective adjustment approach. Table $3 \mathrm{c}$ is the subtraction of Table 3a from Table $3 b$.

\begin{tabular}{|c|c|c|c|c|c|c|c|}
\hline \multirow[t]{2}{*}{ (a) } & & \multicolumn{6}{|c|}{$\begin{array}{c}\text { Forecast UVI } \\
\text { (without subjective adjustment) }\end{array}$} \\
\hline & & $\begin{array}{l}\text { UVI } 0 \sim 2 \\
\dot{\text { minimal }}\end{array}$ & $\begin{array}{l}\text { UVI } 3 \sim 4 \\
\text { low }\end{array}$ & $\begin{array}{l}\text { UVI } 5 \sim 6 \\
\text { moderate }\end{array}$ & $\begin{array}{c}\text { UVI 7 9 } \\
\text { high }\end{array}$ & $\begin{array}{c}\text { UVI 10 -15 } \\
\text { very high }\end{array}$ & Total \\
\hline \multirow{2}{*}{ 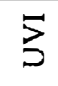 } & UVI $0 \sim 2$ & 19 & 29 & 25 & 4 & 5 & 82 \\
\hline & UVI $3-4$ & 10 & 32 & 62 & 25 & 4 & 133 \\
\hline \multirow{4}{*}{$\begin{array}{l}\vec{D} \\
\stackrel{2}{2} \\
\mathscr{d} \\
\stackrel{0}{0}\end{array}$} & UVI $5 \sim 6$ & 11 & 56 & 139 & 49 & 10 & 265 \\
\hline & UVI 7 9 & 16 & 15 & 101 & 136 & 40 & 308 \\
\hline & UVI $10-15$ & 3 & 1 & 6 & 35 & 47 & 92 \\
\hline & Total & 59 & 133 & 333 & 249 & 106 & 880 \\
\hline
\end{tabular}

\begin{tabular}{|c|c|c|c|c|c|c|c|}
\hline \multirow[t]{2}{*}{ (b) } & & \multicolumn{6}{|c|}{$\begin{array}{c}\text { Forecast UVI } \\
\text { (with subjective adjustment) }\end{array}$} \\
\hline & & $\begin{array}{l}\text { UVI 0 -2 } \\
\text { minimal }\end{array}$ & $\begin{array}{c}\text { UVI } 3 \sim 4 \\
\text { low }\end{array}$ & $\begin{array}{l}\text { UVI } 5 \sim 6 \\
\text { moderate }\end{array}$ & $\begin{array}{c}\text { UVI 7 9 } \\
\text { high }\end{array}$ & $\begin{array}{l}\text { UVI 10 15 } \\
\text { yery high }\end{array}$ & Total \\
\hline \multirow{6}{*}{ 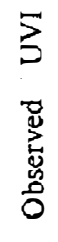 } & UVI $0 \sim 2$ & 23 & 28 & 25 & 5 & 1 & 82 \\
\hline & UVI 3-4 & 9 & 33 & 60 & 26 & 5 & 133 \\
\hline & UVI $5 \sim 6$ & 5 & 55 & 137 & 55 & 13 & 265 \\
\hline & UVI $7 \sim 9$ & 7 & 15 & 96 & 147 & 43 & 308 \\
\hline & UVI 10 15 & 1 & 1 & 7 & 30 & 53 & 92 \\
\hline & Total & 45 & 132 & 325 & 263 & 115 & 880 \\
\hline
\end{tabular}

\begin{tabular}{|c|c|c|c|c|c|c|c|}
\hline \multirow[t]{2}{*}{ (c) } & & \multicolumn{6}{|c|}{$\begin{array}{c}\text { Forecast UVI } \\
\text { (b) - (a) }\end{array}$} \\
\hline & & $\begin{array}{l}\text { UV1 } 0 \sim 2 \\
\text { minimal }\end{array}$ & $\begin{array}{c}\text { UVl } 3 \sim 4 \\
\text { low } \\
\end{array}$ & $\begin{array}{l}\text { UVI 5 -6 } \\
\text { moderate }\end{array}$ & $\begin{array}{c}\text { UVI 7 9 } \\
\text { high }\end{array}$ & $\begin{array}{l}\text { UVI 10 15 } \\
\text { very high }\end{array}$ & Total \\
\hline \multirow{6}{*}{ 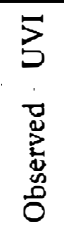 } & UVI $0 \sim 2$ & 4 & -1 & 0 & 1 & -4 & 0 \\
\hline & UVI $3 \sim 4$ & -1 & 1 & -2 & 1 & 1 & 0 \\
\hline & UVI $5 \sim 6$ & -6 & -1 & -2 & 6 & 3 & 0 \\
\hline & UVI $7 \sim 9$ & -9 & 0 & -5 & 11 & 3 & 0 \\
\hline & UVI $10 \sim 15$ & -2 & 0 & 1 & -5 & 6 & 0 \\
\hline & Total & -14 & -1 & -8 & 14 & 9 & 0 \\
\hline
\end{tabular}


trouble is in the extremes. There are five occurrences when the observed UVI was low, but was forecast to be very high, and three occurrences when the observed UVI was very high, but was forecast to be low. With the subjective adjustment approach, improvement in the forecast results for extreme values is achieved (Table 3 ). The number of extremely bad forecast has decreased, and the number of matched cases has increased. It is particularly noteworthy that the number of UVI forecasts in the minimal range has decreased by $24 \%$, while that in the very high range has increased by $9 \%$. Only through a subjective adjustment approach can the forecast UVI be moved from one end to another.

Figure 5 shows the rms difference, correlation coefficient and bias between the forecast and observed UVI at nine UVI monitoring sites during two forecasting periods. The first period is from May 1997 to April 1998, and the second from May 1998 to May 2000. In general, the rms is about $1.7 \sim 2.9$ and $1.9 \sim 2.7$, respectively, for the first and second periods. An rms higher than 2 appear at Alishan, the mountain site, and at sites along the eastern and southern coasts. Further analyses show that rms is higher in spring and summer, but lower in autumn and winter. Such a seasonal cycle is related to not only the change of radiation flux but also the weather system. During winter, UVI is low and the change of weather system is easy to forecast. While in spring and summer, UVI is high and the fast-moving front and afternoon thunderstorm are difficult to predict.

In the meantime, the forecast UVI has a very good correlation with the observed one. The correlation coefficient is about $0.6 \sim 0.76$ and $0.58 \sim 0.73$, respectively, during the first and

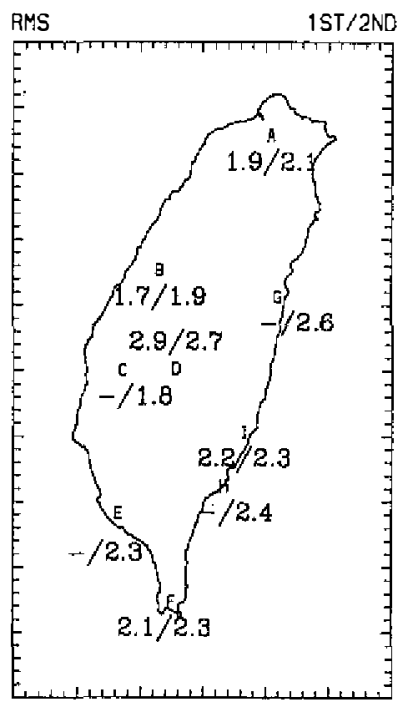

(a)

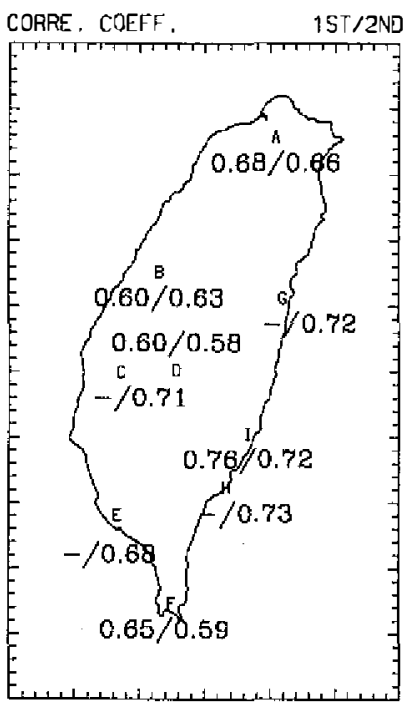

(b)

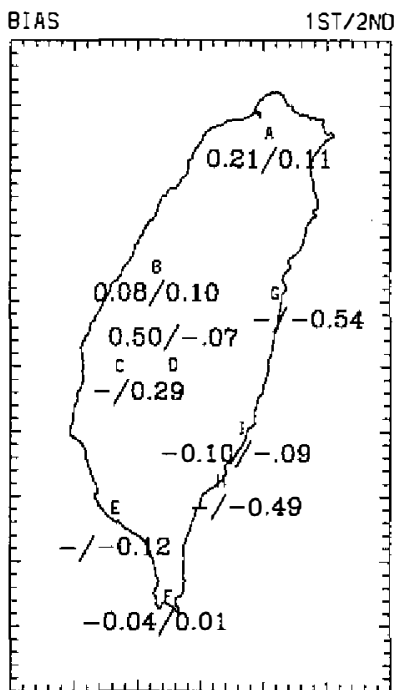

(c)

Fig. 5. (a) The root mean square (rms) difference, (b) correlation coefficient and (c) bias between the forecast and observed UVIs during two forecasting periods. First period is May 1997 April 1998. Second period is May 1998 May 2000. A dash indicates no data. 
second forecasting periods. The bias of forecast UVI from the observed one is generally quite low, at about $-0.1 \sim 0.5$ and $-0.54 \sim 0.29$, respectively, during the first and second forecasting periods. In all, we tend to forecast higher UVI at Alishan and lower at Hualien and Taitung. Hence the higher rms at these sites. This provides a good direction for future improvement.

To understand how closely the forecast UVI is to the observed value, we calculated the frequency of days with the absolute difference, $|\mathrm{d}|$, equal to 0 , smaller than 1 and 2 . Days with $|d| \leq 2$ accounts for $64 \sim 87 \%$ and $66 \sim 86 \%$, respectively, during the first and second forecasting periods. Furthermore, performance is much better during the winter months. For instance, $77 \sim 95 \%$ of days with $|\mathrm{d}| \leq 2$ occur during November $1998 \sim$ February 1999, but only 56 86\% are during June $\sim$ August 1998. As to days with $|\mathrm{d}| \leq 1$, the frequency of occurrence is about $46 \sim 63 \%$ and $43 \sim 64 \%$. Having $|\mathrm{d}|=0$ is quite difficult. The chance is only about $16 \sim 26 \%$ and $13 \sim 27 \%$, respectively. As expected, the worst record is at Alishan.

Table 4 shows the frequency of days where the forecast UVI in five different ranges matched those observed. We have adopted the convention of setting UVI between $0 \sim 2$ as minimal, $3 \sim 4$ as low, $5 \sim 6$ as moderate, $7 \sim 9$ as high and $10 \sim 15$ as very high (Long et al. 1996). The majority of the observed UVI lie in the moderate and high ranges. In general, 39 $\sim 55 \%$ and $21 \sim 50 \%$ of the forecast UVI match with the observed ones, respectively, during the first and second forecasting periods. The matching frequency increases with the UVI range.

Table 4. Matching frequency for forecast vs. observed UVI at all stations in five different ranges during two forecasting periods.

(a) May 1997

$\sim$ April 1998

\begin{tabular}{|c|c|c|c|c|c|c|c|}
\hline \multirow{2}{*}{\multicolumn{2}{|c|}{ 1) May 199}} & \multicolumn{6}{|c|}{ Forang } \\
\hline & & 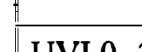 & IVY 2 & Foreca & st UVI & | & \\
\hline \multirow{2}{*}{8} & rer & mimim & low & nouct & ing & a) 1 & sun \\
\hline & Ovi 02 & $39 \%$ & $35 \%$ & $20 \%$ & $5 \%$ & $1 \%$ & 100 \\
\hline \multirow{3}{*}{ 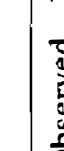 } & W & I0 & 400 & 50 & 100 & $2 \pi$ & 100 \\
\hline & O & 000 & 207 & $43 \%$ & $20 \%$ & $0 \%$ & $100 \%$ \\
\hline & IVI & 00 & 00 & 60 & 2004 & 550 & $100 \%$ \\
\hline
\end{tabular}

(b) May 1998

$\sim$ May 2000

\begin{tabular}{|c|c|c|c|c|c|c|c|}
\hline \multicolumn{2}{|c|}{ May 2000} & minimal & low & moderate & high & very high & sum \\
\hline 5 & UVI $0 \sim 2$ & $21 \%$ & $51 \%$ & $20 \%$ & $7 \%$ & $1 \%$ & $100 \%$ \\
\hline 5 & UVI $3 \sim 4$ & $7 \%$ & $41 \%$ & $39 \%$ & $12 \%$ & $1 \%$ & $100 \%$ \\
\hline $\bar{\Delta}$ & UVI 5 6 & $2 \%$ & $25 \%$ & $45 \%$ & $25 \%$ & $3 \%$ & $100 \%$ \\
\hline 帝 & UVI 7 9 & $1 \%$ & $9 \%$ & $28 \%$ & $50 \%$ & $12 \%$ & $100 \%$ \\
\hline$\tilde{0}^{\infty}$ & UVI $10 \sim 15$ & $0 \%$ & $4 \%$ & $10 \%$ & $43 \%$ & $42 \%$ & $100 \%$ \\
\hline
\end{tabular}


Also, note that the forecast UVI spreads in ranges considerably wider than the observed UVI in the minimal or low range, compared with the mild spreading in the high and very high range. Besides being related to a loose definition of the high and very high range, this phenomenon illustrates the difficulty of capturing cloud effect on UV flux when the weather system changes swiftly. In contrast, when a high-pressure system prevails, the forecast system can easily make a reasonable prediction of high UV index.

\section{SUMMARY AND CONCLUSION}

In general, high erythemally weighted surface UVB flux occurs frequently in summer with the highest UVI occurring at a mountain site and clean coastal sites. Whereas, at the polluted city of Taipei, high UVI occurs much less frequently than at other sites. Comparison of the daily integrals of erythemal fluxes (DUV, $\mathrm{kJ} \mathrm{m}^{-2}$ ) with the data shown in Seekmeryer et al. (1995), we note that July-maximum DUV at eastern and southern coastal sites are close to the July-maximum at Darwin $\left(12.5^{\circ} \mathrm{S}\right)$. But the July-maximum DUV at Taipei is close to the winter-maximum at Melbourne $\left(37.8^{\circ} \mathrm{S}\right)$. In short, the latitudinal difference between Taipei and Taitung is about $2.28^{\circ}$, but the equivalent latitudinal difference between the surface UVB fluxes received at theses two stations is about $25.3^{\circ}$, which illustrates how significant the spatial variation of UVB flux in Taiwan is.

Further analysis suggests that column ozone has a minor spatial variation pattern and is not a major factor affecting the change of surface UVB flux. A flux transmissivity obtained by calculating the ratio of the measured flux for actual weather conditions over the calculated irradiance for clear-sky conditions shows a positive correlation with visibility and sunshine duration hour, and a negative correlation with cloud amount and relative humidity. Among these surface meteorological parameters, change of cloud amount is the dominant factor and is associated with the change of synoptic weather condition and local terrain-forced circulation.

Based on the above results, a UVI forecast system has been developed. Forecast of total ozone is simplified, while subjective and objective cloud-effect adjustment processes are emphasized. The forecast UVI vary closely with the observed value with an acceptable error at nine UVI monitoring sites. Since UVI at a total of 49 locations is forecast daily, more UVI monitoring stations will be set up in order to evaluate more thoroughly the forecast results and to retrieve the cloud-effect adjustment coefficients for each forecast location.

Acknowledgements The author is indebted to the Environmental Protection Administration of the Executive Yuan of R.O.C. for generously providing all needed instruments and resources to support the development of the UV index monitoring and forecast system in Taiwan. Also, the effort by Congressman Ming-Lone Liu and the Environmental Quality Protection Foundation, a non-profit organization, to promote the UVI forecast and public education program is highly appreciated. The Central Weather Bureau does play an important role in providing necessary total ozone, ozone profile and UV monitoring data and the weather forecast information. The assistance by the experienced meteorologist Mr. L.-Y. Jen on checking daily UVI forecast data is particularly appreciated. The author also wants to thank Prof. A. Kylling for allowing us to use freely the UVSPEC model. Also, Prof. Shaw C. Liu is thanked for 
providing useful suggestions to overhaul the paper. Efforts by Fu-Lei Chen, Hsiu-Wu Chang, Lu-Hwei Lo, and King-Jein Lo in providing necessary data, and Hilary Lee, Hwei-Ping Kou, Pimei Doun, An-Chen Hwang, Chia-Hsu Tu and-Wei-Chung Su in assisting the development of the forecast system and the analysis of the forecast data are deeply appreciated. This paper was finished under the support of EPA-88-L102-03-3-02, EPA-89-U1L1-03-001, NSC 882111-M-002-011 and NSC892111M002009.

\section{REFERENCES}

Austin, J., B. R. Barwell, S. J. Cox, P. A. Hughes, J. R. Knight, G. Ross, and P. Sinclair, 1994: The Diagnosis and forecast of clear sky ultraviolet levels at the Earth's surface. Met. Appl., 1, 321-326.

Bais, A. F., 1997: Absolute spectral measurements of direct solar ultraviolet irradiance with a Brewer spectrophotometer. Applied Optics., 36, 5199-5204.

Borkowski, J. L., 2000: Homogenisation of the Belsk UV-B series (1976-1997) and trend analysis, J. Geophys. Res., 105, 4873-4878.

Chen, G. T. J. 1994: Large-scale circulations associated with the East Asian summer monsoon and the Mei-Yu over South China and Taiwan. J. Meteor. Soc. Japan., 72, 959983.

Feister, U., and R. Grewe, 1995: Spectral albedo measurements in the UV and visible region over different types of surfaces. Photochem. and Photobiol., 62, 736-744.

Jendritzky, G., H. Staiger, and K. Bucher, 1997: UV prognosis and UV index services in Europe. Skin Cancer and UV Radiation, In: P. Altmeyer, K. Hoffmann and M. Stucker (Eds.), 37-49.

Kerr, J. B., and C. T. McElroy, 1993: Evidence for large upward trends of ultraviolet-B radiation linked to ozone depletion. Science, 262, 1032-1034.

Koepke, P., A. Bais, D. Balis, M. Buchwitz, H. De Backer, X. de Cabo, P. Eckert, P. Eriksen, D. Gillotay, A. Heikkila, T. Koskela, B. Lapeta, Z. Litynska, J. Lorente, B. Mayer, A. Renaud, A. Ruggaber, G. Schauberger, G. Seclemeyer, P. Seifert, A. Schmalwieser, H. Schwander, K. Vanicek, and M. Weber, 1998: Comparison of models used for UV index calculations. Photochem. and Photobiol., 67, 657-662.

Kylling, A., 1995: UVspec User's Guide, The UVspec Radiative Transfer Program, Edition 0.2 for UVspec version $1.4,34 \mathrm{pp}$, May.

Kylling, A., K. Stamnes, and S.-C. Tsay, 1995: A reliable and efficient two-stream algorithm for spherical radiative transfer: Documentation of accuracy in realistic layered media. J. Atm. Chem., 21, 115-150.

Leszczynski, K., K. Jokela, L. Ylianttila, R. Visuri, and M. Blumthaler, 1998: Erythemally weighted radiometers in solar UV monitoring: Results from the WMO/SYUK intercomparison, Photochem. and Photobiol., 67, 212-221.

Liu, C.M., C.-J. Lin, H.-W. Change and S.-M. Chou, 1995: Ozone monitoring in Taiwan, Atmospheric Ozone as a Climate Gas - General Circulation Model Simulation. In: W.C. Wang and I.S.A. Isaksen (Eds.), NATO ASI Series, Subseries I Global Environmen- 
tal Change, vol. 32, 289-303.

Liu, C.-M., M.-L. Liu, and J.-P. Chen, 1998: The UV Index: Monitoring, Forecast and Public Education, EPA-87-FA04-03-11, pp120. (in Chinese)

Liu, M.-L, and C.-M. Liu, 1997: Long-term Planning on the Air Pollution Control and Study of the Damage Effect on Plant? The UV Index: Monitoring, Forecast and Public Education, EPA-86-FA41-09-E8, pp120. (in Chinese)

Long, C. S., A. J. Miller, H.-T. Lee, J. D. Wild, R. C. Przywarty, and D. Hufford, 1996: Ulraviolet Index forecasts issued by the National Weather Service. Bull. Amer. Meteoro. Soc., 77, 729-748.

McElroy, C. T., J. B. Kerr, L. J. B McArthur, and D. I. Wardle, 1994: Ground-based monitoring of UV-B radiation in Canada, NATO Series, Vol. I 18, Stratospheric Ozone Depletion/UV-B Radiation in the Biosphere. In: R. H. Biggs and M. E. B. Joyner (Eds.), 271 $-282$.

McKinley, A., and B. L. Diffey, 1987: A reference action spectrum for ultraviolet induced erythema in human skin, Human Exposure to Ultraviolet Radiation: Risks and Regulations. In: W. F. Passchier \& B. F. M. Bosnajakovic (Eds.), 83-87.

Schwander, H., P. Koepke, and A. Ruggaber, 1997: Uncertainties in modeled UV irradiances due to limited accuracy and availability of input data. J. Geophys. Res., 102(D8), 94199429.

Seckmeyer G., B. Mayer, G. Bernhard, R. L. McKenzie, P. V. Johnston, M. Kotkamp, C. R. Booth, T. Lucas, T. Mesrtechkina, C. R. Roy, H. P. Gies, and D. Tomlinson, 1995: Geographical differences in the UV measured by intercompared spectroradiometers. Geophys. Res. Lett., 22, 1889-1892.

Weihs, P., and A. R. Webb, 1997a: Accuracy of spectral UV model calculations, 1. Consideration of uncertainties in input parameters. J. Geophys. Res., 102 (D1), 1541-1550.

Weihs, P., and A. R. Webb, 1997b: Accuracy of spectral UV model calculations, 2. Comparison of UV calculations with measurements. J. Geophys. Res., 102 (D1), 1551-1560.

WMO, 1995: Report of the WMO Meeting of Experts on UV-B Measurements, Data Quality and Standardization of UV Indices, Les Diablerets, Switzerland, 25-28 July, 1994, WMO Global Atmosphere Watch Report No. 95. 